\title{
Assessment of premenstrual syndrome among female students in Southeast Nigeria
}

\author{
Kelechi Martins Nworie', Deborah Oyine Aluh², Chinyere Abigail Onyekwum \\ 'Pharmaceutical Outcomes Research Group, Faculty of Pharmacy, University of Nigeria, Nsukka, Nigeria \\ 2Department of Clinical Pharmacy and Pharmacy Management, Faculty of Pharmaceutical Sciences, University of Nigeria, Nsukka, \\ Nigeria
}

\begin{abstract}
Introduction: Premenstrual syndrome (PMS) and premenstrual dysphoric disorder (PMDD) are premenstrual disorders characterized by a cyclical pattern of severe premenstrual symptoms experienced by women, which typically occurs during the days prior to menstruation and ends at the onset of menses. These symptoms may be unbearable in some women and hinder normal daily life including personal relationships, social activities, work and academic activities. The aim of the present study was to assess the prevalence and severity of PMS among female students. PMS and PMDD were diagnosed using the Calendar of Premenstrual Experiences (COPE) form. Participants were requested to complete the form for two consecutive menstrual cycles. A cross-sectional descriptive study was conducted in 480 female students (aged 15 to 45 years) at the University of Nigeria, Nsukka.

Results: Of the 480 participants, 206 (42.9\%) women met the criteria for diagnosis of PMS, and 274 (57.1\%) did not meet the criteria for PMS. Among participants with PMS, 98 (47.6\%) women met the criteria for severe PMS or PMDD. In women with PMS, the most prevalent symptoms were trouble concentrating (85.0\%), irritability (79.2\%), abdominal bloating (75.3\%), aches and pains (70.0\%), mood swings (69.2\%), breast tenderness (69.2\%), and food craving (68.0\%).

Conclusions: The prevalence of PMS, as well as PMDD, was high among female students in Nigeria.

Key words: disorders, symptoms, menstruation, cyclical.
\end{abstract}

Kelechi Martins Nworie, Pharmaceutical Outcomes Research Group, Department of Clinical Pharmacy and Pharmacy Administration, Faculty of Pharmacy, University of Nigeria, Nsukka, Nigeria, Phone: +234(0)8063728781, E-mail: nworiekelechimartins@gmail.com 


\section{Introduction}

During reproductive age, women generally experience one or more symptoms including psychological, behavioral and physical symptoms regularly during the early menstruation period. Premenstrual syndrome (PMS) is a commonly used term that has been variably defined. The PMS is a condition characterized by distressing psychological, behavioral and physical symptoms in the absence of any underlying diseases, which develops within the luteal phase of the menstrual cycle and resolves shortly after menstruation [1]. These symptoms commonly include depression, irritability, bloating, and isolation, among others. The luteal phase begins after ovulation and ends at the onset of menstruation. The American College of Obstetricians and Gynecologists (ACOG) (2009) includes mainly psychiatric and physical symptoms in defining PMS [2], and stipulated that $85 \%$ of menstruating women experience at least one premenstrual symptom which may manifest in varying degrees during their reproductive lives [2]. The American Psychiatric Association (APA) emphasizes psychiatric symptoms as criteria for defining PMS [3].

The severity of premenstrual symptoms can vary very significantly from woman to woman. In PMS, premenstrual symptoms may be severe in some women and can alter normal daily functioning in such women [4]. These symptoms can affect work and academic performances, increase medical expenses, and lower the quality of life in women with PMS [4]. Premenstrual dysphoric disorder (PMDD) is severe PMS, mostly with predominating psychiatric symptoms [3]. In PMDD, the symptoms may be very severe to manifest serious disability and often require pharmacological intervention. In the luteal phase of the menstrual cycle, approximately $80 \%$ of women indicate physical and psychological symptoms without impairment in daily activities [5]. A study reported that $36 \%$ of women met the criteria for diagnosis of PMS at a 1-year follow-up [6]. Studies have shown that approximately $30-50 \%$ of women experience a mild to moderate form of PMS for several days [7], and PMDD is prevalent in $3-8 \%$ of women [8].

Despite the common nature of PMS, its etiology still remains unknown [9]. The contributions of socio-cultural and genetic factors are also unclear. Although no genes have been identified, twin studies suggest that there could be possible heritability to PMS [10]. In addition to genetic predisposition, it is quite possible that socio-cultural factors and a woman's personal expectations could influence her premenstrual symptoms [11]. The PMS is likely cross-cultural, with PMS reported across different ethnic and cultural societies [12]. The symptoms may vary among women or groups of women. Hence, the predisposing factors for the development of PMS have not been clearly distinguished. Basically, the body tissues of a woman become sensitive to changes in hormone levels. Changes in estrogen and progesterone levels throughout the menstrual cycle can influence the chemicals in the brain such as serotonin, which affect mood [10]. Studies suggest that changes in estrogen and progesterone levels trigger symptoms of PMS
$[11,12]$. A credible explanation for this is that there is recurrence of PMS symptoms during progesterone therapy in post-menopausal women who were previously diagnosed with PMS $[13,14]$. The cyclic effect of estrogen and progesterone on serotonin, $\gamma$-aminobutyric acid, and dopamine systems may be the cause of changes in mood, and these may also affect the renin-angiotensin system (RAS), which likewise may be the cause of symptoms such as bloating, swelling and weight gain that occur during PMS [11, 15, 16]. However, studies have found no significant difference in estrogen and progesterone levels of women with and without PMS [6]; women with PMS do not have higher levels of estrogen and progesterone than women without PMS. Thus, it still remains unclear why some women develop PMS and others do not. The most probable explanation based on several studies is that women who develop PMS are more sensitive to normal hormonal changes during the menstrual cycle [10-12]. Additionally, gonadotropin-releasing hormone analogues are involved in PMS as they suppress the estrogen levels $[14,17]$.

The diagnostic criteria are worthy of mention. There is no single symptom characteristic for diagnosis of PMS or PMDD [3], but, rather, the cyclic occurrence of a symptom complex. Diagnosis focuses on the symptom complex which includes physical and behavioral symptoms for PMS, and mood symptoms for PMDD [1-3]. Generally, symptoms must occur prior to menstruation and resolve rapidly with the onset of menstrual flow, and should not occur until after ovulation. One study found that most women presenting with the chief complaint of PMS actually do not have a symptom-free window following the onset of menses and therefore do not meet the criteria for PMS/PMDD [18]. The symptom complex may or may not interfere with work, school, relationships, or some aspects of daily living. The symptom complex must not occur as a result of an underlying medical condition. Common medical conditions to be considered in diagnosis of PMS include hypothyroidism, substance abuse disorders, bipolar disorders, depressive disorders and anxiety disorders. Confirmation of these conditions entails a careful medical history and consultations as required. Prospective recordings are critical in this determination $[2,3]$. Several calendars have been validated, including the Calendar of Premenstrual Experiences (COPE), the Daily Record of Severity of Problems (DRSP), and the Prospective Record of the Impact and Severity of Menstruation (PRISM) [19, 20]. However, these methods require immense time and effort since patients have to report their symptoms daily for at least two menstrual cycles.

Recent treatment of PMS focuses on pharmacologic interventions in addition to non-pharmacologic interventions. The mainstay of pharmacological therapy is the SSRIs. Other treatments include the use of antidepressants, NSAIDS, oral contraceptives, etc. Non-pharmacological interventions focus on modification of lifestyle for relieving symptoms of PMS especially in mild to moderate degrees. These include exercise, yoga, intake of vitamins $\left(\mathrm{A}, \mathrm{E}\right.$ and $\left.\mathrm{B}_{6}\right)$ and mineral supplements ( $\mathrm{Ca}$ and $\mathrm{Mg}$ ). In addition, restricted intake of salt, caffeine, sweet and fatty foods is highly recommended. 
Research studies in PMS have been extensively evaluated in most Western countries, but to a limited extent in Africa. In Nigeria, due to its personal nature, women regard PMS as a common problem not requiring medical attention. It is also one of the major causes of low academic performance and class absenteeism among young female students [21]. Therefore, in order to increase awareness of menstruation-related symptoms and enhance the quality of life of women of reproductive age, this study is aimed at assessing the prevalence of PMS among reproductive aged females and investigating the frequency and severity of symptoms experienced by women with PMS.

\section{Material and methods}

\section{Selection of participants}

This cross-sectional descriptive study was conducted at the University of Nigeria, Nsukka, Enugu state. A total of 480 healthy reproductive aged ( 15 to 45 years) female pharmacy students from the University of Nigeria, Nsukka were recruited for the study. The study duration was from March to October 2017. Written informed consent was obtained from all participants; those who were pregnant, on contraception, amenorrheic, and with current debilitating medical, psychiatry or gynecological problems were excluded from the study.

\section{Study design}

The questionnaires were distributed in the respective female students' hall of residence. First, the study was individually explained to the subjects and they were given assurance of confidentiality of their information. Subjects' characteristics including socio-demographics, menstrual history, and others were collected according to pro forma. The subjects were briefed on how to appropriately complete the self-reported COPE form throughout two menstrual cycles. Each subject was instructed to record her experiences of each symptoms in COPE only during the evening (previous $12-18 \mathrm{~h}$ ) as absent, mild, moderate or severe. For monitoring, each subject was visited after completion of the COPE form for the first menstrual cycle. The first set of questionnaires was collected and reviewed for errors; these errors were further explained to the subject to prevent similar errors in the second set of questionnaires. They further completed the COPE form for the next consecutive menstrual cycle. At the end of the second menstrual cycle, the second set of questionnaires was collected and assessed for PMS.

\section{Study instrument}

The COPE is another valid and reliable tool for diagnosis of PMS [22-24]. It is a single sheet calendar diary consisting of 21 premenstrual symptoms to assess psychological, physical, and behavioral factors for each day of the menstrual cycle [21]. The premenstrual symptoms are recorded by self-report visual analogue scales [21]. The COPE scoring for each symptom is a 3 -point rating scale: absent $=0$, present $=1$, severe (enough to distort daily routine in various aspects) $=2$. The COPE is one of the most acceptable prospective records for clinical and research investigations of PMS [24].

\section{Criteria for PMS}

Clinical criteria for diagnosis of PMS have been established by ACOG [2]. According to ACOG, criteria for diagnosis of PMS include at least one moderate to severe mood symptom and one physical symptom [2]. Mood or affective symptoms include depression, anxiety, irritability, confusion, anger outbursts, and loneliness. Somatic pain symptoms are abdominal bloating, breast tenderness, headache, muscle pain and weight gain.

\section{Assessment of PMS}

The PMS was assessed in subjects with COPE for two consecutive menstrual cycles according to the DSM-IV. Subjects were considered to have PMS if they had at least one severe (score rating $=2$ ) psychological symptom (Items 1 to 8 of COPE), and one severe (score rating $=2$ ) physical symptoms (Items 9 to 13 of COPE) in the luteal phase of the menstrual cycle, but absent in the follicular phase. Subjects with five or more symptoms in total including one severe (score rating $=2$ ) mood symptom (Items 1 to 4 of COPE) in the luteal phase of the menstrual cycle, but absent in the follicular phase, were considered to have severe PMS or PMDD [23].

\section{Ethical clearance}

The study was approved by the institutional ethical review committee.

\section{Statistical analysis}

The collected data were coded into Microsoft Excel and analyzed using SPSS v. 16. Categorical variables were expressed as frequency and percentage.

\section{Results}

\section{Socio-demographic data}

A total of 480 respondents were recruited for the study. Table I shows the characteristics of respondents. The mean age was $20 \pm 2$ years. The majority of the respondents were single (95.0\%), Christians (97.5\%), and $36.7 \%$ were in the second year of their study. Most of the respondents (62.5\%) had menarche at age $13-16$ years, and $54.2 \%$ had the menstrual interval between 25 and 29 days.

\section{Prevalence of premenstrual syndrome}

Out of the 480 respondents surveyed, 206 (42.9\%) women met the criteria for diagnosis of PMS. Among the women with PMS, 98 (47.6\%) had symptoms severe enough to interfere and cause impairment in normal daily activities, and hence met the criteria for severe PMS or PMDD. The remaining 108 (52.4\%) women with PMS had mild or moderate PMS.

\section{Prevalence of premenstrual symptoms}

Table II also shows the premenstrual symptoms experienced by respondents with PMS. The most prevalent symptoms in respondents with PMS were trouble concentrating (85.0\%), irritability (79.2\%), abdominal bloating (75.3\%), aches and pains (70.0\%), mood swings (69.2\%), breast ten- 
Table I. Characteristics of respondents

\begin{tabular}{|c|c|c|}
\hline Characteristics & $\begin{array}{l}\text { Frequency } \\
(n=480)\end{array}$ & Percentage (\%) \\
\hline \multicolumn{3}{|l|}{ Age [years]: } \\
\hline $15-17$ & 52 & 10.8 \\
\hline $18-20$ & 200 & 41.7 \\
\hline $21-23$ & 184 & 38.3 \\
\hline$>23$ & 44 & 9.2 \\
\hline \multicolumn{3}{|l|}{ Marital status: } \\
\hline Single & 456 & 95.0 \\
\hline Married & 24 & 5.0 \\
\hline \multicolumn{3}{|l|}{ Religion: } \\
\hline Christian & 468 & 97.5 \\
\hline Muslim & 12 & 2.5 \\
\hline \multicolumn{3}{|l|}{ Academic level: } \\
\hline First year & 60 & 12.5 \\
\hline Second year & 176 & 36.7 \\
\hline Third year & 88 & 18.3 \\
\hline Fourth year & 96 & 20.0 \\
\hline Final year & 60 & 12.5 \\
\hline \multicolumn{3}{|c|}{ Menarche age [years]: } \\
\hline $9-12$ & 132 & 27.5 \\
\hline $13-16$ & 300 & 62.5 \\
\hline$>16$ & 48 & 10.0 \\
\hline \multicolumn{3}{|c|}{ Menses duration [days]: } \\
\hline $1-3$ & 8 & 1.7 \\
\hline $4-6$ & 420 & 87.5 \\
\hline$>6$ & 52 & 10.8 \\
\hline \multicolumn{3}{|c|}{ Menstrual interval [days]: } \\
\hline $1-24$ & 96 & 20.0 \\
\hline $25-29$ & 260 & 54.2 \\
\hline $30-34$ & 76 & 15.8 \\
\hline$>34$ & 48 & 10.0 \\
\hline
\end{tabular}

derness (69.2\%), and food craving (68.0\%). Crying spells (19.3\%) and insomnia (20.2\%) were the least prevalent symptoms in respondents with PMS.

\section{Adaptive coping strategies}

Table III shows the strategies adopted by respondents. The most common strategies of all women with PMS were warm or cold shower (96.3\%), listening to music (94.2\%), meditation $(81.0 \%)$, self-medication $(79.1 \%)$, and exercise (61.5\%). Warm or cold shower $(80.0 \%)$ and listening to music (70.0\%) were most prevalent in respondents without PMS.

\section{Effect of premenstrual symptoms on life activities}

Table IV shows the consequences of premenstrual symptoms for normal life activities of respondents. Forty percent of respondents indicated that the symptoms affect their social interactions, while general personality is affected in $66.1 \%$. More crucially, respondents (65.4\%) indicated that symptoms often interfered with their academic presence. Twenty-nine percent reported that it affected their academic performance.

\section{Discussion}

The prevalence of PMS in our study was $42.9 \%$. According to ACOG, 30-40\% of menstruating women have premenstrual symptoms severe enough to affect their daily life activities [1]. The prevalence in our study (42.9\%) did not differ much from the prevalence stated by ACOG. However, the prevalence of PMDD among PMS women in the present study differs greatly from the ACOG report. The present study reported $47.6 \%$ prevalence of PMDD among PMS women, while ACOG estimated 3-4\% prevalence [1]. The PMS estimates vary widely in the literature because of differences in study instruments, symptom patterns, and the use of prospective or retrospective protocols. Observations from the present study are similar to a study conducted in Nigeria among medical students, in which $36 \%$ of the subjects had DSM-IV-TR PMDD [25]. Again, another study among medical students in Saudi Arabia found that approximately $36 \%$ of surveyed cases had PMS, based on the ACOG criteria [26]. Nevertheless, the rate of severe PMS or PMDD in the present study is relatively high when compared to findings in other studies performed among medical and non-medical students, the reported PMDD ranging from $6 \%$ to $18 \%$ of their sample population $[27,28]$. Assuming that studying a medical course is in itself stressful, this could have contributed to the high rate of PMDD observed in our study. Medical students supposedly have more study-related stress, and psychosocial stress levels are reported to be related to severity of PMS [29]. Many lifestyle factors which included sleep, daily physical activity, and food intake have been associated with severe PMS or PMDD. Arguing that pharmacy and medical students are highly predisposed to these factors could provide evidence that contributed to the high rate of PMDD among the students in our study.

The prevalence of PMS in the present study was found to be similar, considering previous findings from other studies in young women in which respondents showed a high prevalence of PMS [30-33]. However, the assessment of PMS and PMDD in 1187 Japanese women using a premenstrual symptom questionnaire reported prevalence of $5.3 \%$ and $1.2 \%$ respectively [34]. Another study in Asia conducted among 423 Thai nurses reported a prevalence of $25.1 \%$ [35]. A previous study of 200 students (aged 16 to 31 years) from the University of Calabar, Nigeria reported that $85.5 \%$ regularly experienced symptoms consistent with those of PMS [36]. In another study among Nigerian students, $94.8 \%$ of the study respondents were diagnosed with PMS [37]. In a metaanalysis of 17 studies, prevalence of PMS was reported as $40 \%$ in Europe, $85 \%$ in Africa, $46 \%$ in Asia and 60\% in South America [38]. Findings from these studies suggest that the prevalence of PMS varies greatly. An explanation for this great disparity lies in the study tool utilized and difference in sample populations [38]. Considering the different tools 
Table II. Prevalence of symptoms in respondents with premenstrual syndrome

\begin{tabular}{|c|c|c|c|c|}
\hline No. & Complained symptoms & PMS $(n=206)$ & Mild and moderate PMS ( $n=108)$ & Severe PMS or PMDD ( $n=98)$ \\
\hline \multicolumn{5}{|c|}{ Psychological symptoms } \\
\hline 1 & Depression & 45.8 & 38.4 & 55.2 \\
\hline 2 & Anxiety & 64.2 & 40.0 & 47.0 \\
\hline 3 & Irritability & 79.2 & 57.2 & 63.4 \\
\hline 4 & Anger outbursts & 43.9 & 25.4 & 75.8 \\
\hline 5 & Mood swings & 69.2 & 48.6 & 63.5 \\
\hline 6 & Lethargy/fatigue & 73.3 & 62.5 & 88.1 \\
\hline 7 & Trouble concentrating & 85.0 & 30.8 & 94.3 \\
\hline 8 & Tension & 65.0 & 55.6 & 62.6 \\
\hline \multicolumn{5}{|c|}{ Physical symptoms } \\
\hline 9 & Breast tenderness & 69.2 & 48.3 & 71.0 \\
\hline 10 & Headache & 54.7 & 50.0 & 64.3 \\
\hline 11 & Abdominal bloating & 75.3 & 61.1 & 90.0 \\
\hline 12 & Aches and pains & 70.0 & 56.5 & 80.9 \\
\hline 13 & Swelling in extremities & 32.8 & 16.3 & 39.4 \\
\hline \multicolumn{5}{|c|}{ Behavioral symptoms } \\
\hline 14 & Appetite change & 64.2 & 45.7 & 77.1 \\
\hline 15 & Food craving & 68.0 & 59.3 & 70.2 \\
\hline 16 & Insomnia & 20.2 & 14.0 & 29.2 \\
\hline 17 & Crying spells & 19.3 & 17.6 & 28.6 \\
\hline 18 & Short temper & 50.8 & 57.7 & 45.2 \\
\hline 19 & Forgetfulness & 32.5 & 24.2 & 39.0 \\
\hline 20 & Lack of interest & 51.8 & 67.8 & 36.5 \\
\hline 21 & Isolation & 41.7 & 43.6 & 50.4 \\
\hline
\end{tabular}

that have been used in many studies and designs of studies based on limited samples, further research needs to consider the prevalence of PMS in various countries of the world.

In the assessment of premenstrual symptoms among pre-medical students in Nigeria conducted by Ikeako et al. $65.8 \%$ of students had pelvic discomfort, $59.5 \%$ had breast fullness, $41.0 \%$ had mood changes, $27.9 \%$ had irritation and $20.8 \%$ had fatigue [39]. The most prevalent symptoms of women with PMS in the present study were troubled concentration, irritability and lethargy/fatigue, while the least frequent symptom was crying spells. Abdominal bloating was the most common symptom both in women with mild or moderate PMS and PMDD. The psychiatric symptom (troubled concentration) observed in the present study may be associated with the relatively young age of the students. A similar study in Iran reported that psychiatric symptoms were the predominating symptoms in younger respondents with PMS [40].

Promoting a positive attitude toward the management of PMS among young women is a priority. Socio-cultural
Table III. Strategies adopted by respondents for managing symptoms

\begin{tabular}{|l|c|c|}
\hline $\begin{array}{l}\text { Adopted strategy } \\
\text { Psychological interaction: }\end{array}$ & $\begin{array}{c}\text { PMS } \\
(n=206)\end{array}$ & $\begin{array}{c}\text { No PMS } \\
(n=274)\end{array}$ \\
\hline $\begin{array}{l}\text { Praying } \\
\text { Meditation }\end{array}$ & 79.5 & 65.8 \\
\hline $\begin{array}{l}\text { Listening to music } \\
\text { Body manipulation: }\end{array}$ & 91.0 & 50.8 \\
\hline Massage & 94.2 & 70.0 \\
\hline Exercise & 59.8 & 49.2 \\
\hline Warm or cold shower & 61.5 & 50.8 \\
\hline Medical care: & 96.3 & 80.0 \\
\hline Visit to hospital & 13.8 & \\
\hline Visit to pharmacy & 62.0 & 27.5 \\
\hline Herbal remedies & 14.4 & 3.9 \\
\hline Self-medication & 79.1 & 52.5 \\
\hline
\end{tabular}


Table IV. Effect of premenstrual symptoms on participants

\begin{tabular}{|l|c|c|}
\hline Outcome & Mild and moderate PMS $(n=108)$ & Severe PMS or PMDD $(n=98)$ \\
\hline It affects my academic presence in class & 64.5 & 73.3 \\
\hline It affects my academic performance & 35.8 & 29.2 \\
\hline It affects my social interactions & 40.0 & 72.5 \\
\hline It affects my general personality & 66.1 & 55.0 \\
\hline
\end{tabular}

factors influence self-care practices of young women [41]. However, some women have developed their own strategy to cope with premenstrual symptoms. According to the present study, adaptive coping strategies during premenstrual symptom episodes include psychological interaction: praying, meditation, music; body manipulation: massage, exercise, warm/cold shower; and medical care: visit to hospital or pharmacy, herbal remedies and self-medication. Studies have shown that superstitious beliefs and misinterpretation are common in the process of menstruation and self-care practice [41].

The proportion of respondents who avoided social activities and had poor academic attendance and performance is congruent with findings from other studies [42, 43]. Prior stress could induce or worsen symptoms of premenstrual syndrome [44], which could be a plausible explanation of the high prevalence of PMS observed in medical and pharmacy students.

\section{Conclusions}

Findings from the present study revealed that the prevalence of PMS in female students was high (42.9\%). The PMDD was also high (47.6\%) in women with PMS. The study sample comprised female pharmacy students who indulge mostly in rigorous academic activities. The findings from this study suggest that stressful lifestyle and events may be a predisposing factor to PMS or PMDD. Further research should be conducted to effectively determine whether a reduction in stress would be beneficial for the occurrence of PMS or PMDD.

\section{Conflict of interest}

The authors declare no conflict of interest.

\section{References}

1. O’Brien PM, Bäckström T, Brown C, et al. Towards a consensus on diagnostic criteria, measurement and trial design of the premenstrual disorders: the ISPMD Montreal consensus. Arch Womens Ment Health 2011; 14: 13-21.

2. American College of Obstetricians and Gynecologists. Guidelines for Women's Health Care: A Resource Manual. $4^{\text {th }}$ ed. DC: American College of Obstetricians and Gynecologists, Washington 2014: 607-13.

3. American Psychiatric Association. Diagnostic and Statistical Manual of Mental Disorders. $5^{\text {th }}$ ed. DC: American Psychiatric Association, Washington 2013.
4. Rapkin AJ, Winer SA. Premenstrual syndrome and premenstrual dysphoric disorder: quality of life and burden of illness. Exp Rev Pharmacoeconom Outcomes Res 2014; 9: 157-70.

5. Wittchen HU, Becker E, Lieb R, Krause P. Prevalence, incidence and stability of premenstrual dysphoric disorder in the community. Psychol Med 2002; 32: 119-32.

6. Potter J, Bouyer J, Trussell J, Moreau C. Premenstrual syndrome prevalence and fluctuation over time: results from a French population-based survey. J Womens Health (Larchmt) 2009; 18: 31-9.

7. Logue CM, Moos RH. Perimenstrual symptoms: prevalence and risk factors. Psychosom Med 1986; 48: 388-414.

8. Rapkin AJ, Lewis EI. Treatment of premenstrual dysphoric disorder. Womens Health 2013; 9: 537-56.

9. Direkvand-Moghadam A, Sayehmiri K, Delpisheh A, Kaikhavandi S. Epidemiology of premenstrual syndrome (PMS) - a systematic review and meta-analysis study. J Clin Diagn Res 2014; 8: 106-9.

10. Jahanfar S, Lye MS, Krishnarajah IS. The heritability of premenstrual syndrome. Twin Res Hum Genet 2011; 14: 433-6.

11. Davis C. Premenstrual distress among Caucasian, African-American and Chinese women. J Women's Health Care 2014; 3: 181.

12. Dennerstein L, Lehert P, Heinemann K. Global study of women's experiences of premenstrual symptoms and their effects on daily life. Menopause Int 2011; 17: 88-95.

13. Hammarbäck S, Bäckström T, Holst J, von Schoultz B, Lyrenäs S. Cyclical mood changes as in the premenstrual tension syndrome during sequential estrogen-progestagen postmenopausal replacement therapy. Acta Obstet Gynecol Scand 1985; 64: 393-7.

14. Segebladh B, Borgstrom A, Nyberg S, Bixo M, Sundstrom-Poromaa I. Evaluation of different add-back estradiol and progesterone treatment in patients with premenstrual dysphoric disorder. Am J Obstet Gynecol 2009; 201:139.e1-8.

15. Roca CA, Schmidt PJ, Bloch M, Rubinow DR. Implications of endocrine studies in premenstrual syndrome. Psychiatr Ann 1996; 26: 576-80.

16. Kumar P, Sharma A. Gonadotropin-releasing hormone analogs: understanding advantages and limitations. J Hum Reprod Sci 2014; 7: 170-4.

17. Sundstrom I, Nyberg S, Bixo M, Hammarback S, Backstrom T. Treatment of premenstrual syndrome with gonadotropin-releasing hormone agonist in a low dose regimen. Acta Obstet Gynecol Scand 1999; 78: 891-9.

18. Yonkers KA, O'brien PMS, Eriksson E. Premenstrual syndrome. Lancet 2008; 371: 1200-10.

19. Cunningham J, Yonkers KA, O’Brien S, Eriksson E. Update on research and treatment of premenstrual dysphoric disorder. Harv Rev Psychiatry 2009; 17: 120-37.

20. Rapkin AJ, Winer SA. Premenstrual syndrome premenstrual dysphoric: quality of life and burden of illness. Exp Rev Pharmacoeconom Outcomes Res 2009; 9: 157-70. 
21. Alemu SM, Habtewold TD, Haile YG. Mental and reproductive health correlates of academic performance among debre Berhan University Female Students, Ethiopia: the case of premenstrual dysphoric disorder. BioMed Res Int 2017; 2017: 9348159.

22. Mortola JF, Girton L, Beck L, Yen SS. Diagnosis of premenstrual syndrome by a simple, prospective, and reliable instrument: the calendar of premenstrual experiences. Obstetrics Gynecol 1990; 76: 302-7.

23. Michael F, Shaw WS. Measurement properties of the calendar of premenstrual experience in patients with premenstrual syndrome. J Reprod Med 2002; 47: 279-89.

24. Oo HH, Sein MT, Ohnmar, Aung A. Assessment of premenstrual syndrome among reproductive aged Myanmar women. Asian J Med Sci 2016; 7: 39-43.

25. Issa BA, Yussuf AD, Olatinwo AW, Ighodalo M. Premenstrual dysphoric disorder among medical students of a Nigerian university. Ann Afr Med 2010; 9: 118-22.

26. Balaha MH, Amr MA, Saleh AI, Moghannum M, Saab AI, Muhaidab N. The phenomenology of premenstrual syndrome in female medical students: a cross sectional study. Pan Afr Med J 2010; 5: 4 .

27. Adewuya AO, Loto OM, Adewumi TA. Premenstrual dysphoric disorder amongst Nigerian university students: prevalence, comorbid conditions, and correlates. Arch Womens Ment Health 2008; 11: 13-8.

28. Bakhshani NM, Mousavi MN, Khodabandeh G. Prevalence and severity of premenstrual symptoms among Iranian female university students. J Pak Med Assoc 2009; 59: 205-8.

29. Deuster PA, Adera T, South-Paul J. Biological, social, and behavioral factors associated with premenstrual syndrome. Arch Fam Med 1999; 8: 122-8.

30. Konapur KS, Nagaraj. Dysmenorrhea and premenstrual syndrome: frequency and effect on daily activities of adolescent girls in rural areas of Bangalore. Int J Med Sci Public Health 2014; 3: 1255-8.

31. Bakhshani NM, Mousavi MN, Khodabandeh G. Prevalence and severity of premenstrual symptoms among Iranian female university students. J Pak Med Assoc 2009; 59: 205-8.

32. Sharma P, Malhotra C, Taneja DK, Saha R. Problems related to menstruation amongst adolescent girls. Indian J Pediatr 2008; 75 : 125-9.

33. Chandraratne NK, Gunawardena NS. Premenstrual syndrome: the experience from a sample of Sri Lankan adolescents. J Pediatr Adolesc Gynecol 2011; 24: 304-10.

34. Takeda T, Tasaka K, Sakata M, Murata Y. Prevalence of premenstrual syndrome and premenstrual dysphoric disorder in Japanese women. Arch Women's Mental Health 2006; 9: 209-12.

35. Chayachinda C, Rattanachaiyanont M, Phattharayuttawat S, Kooptiwoot S. Premenstrual syndrome in Thai nurses. J Psychosom Obstet Gynaecol 2008; 29: 203-9.

36. Umoiyoha AU, Antai AB, Udezi AW, Ekanem EE, Okon UJ. Premenstrual syndrome: prevalence in students of the University of Calabar, Nigeria. African J Biomed Res 2004; 7: 45-50.

37. Elalaiye B, Eigbefoh J, Eifediyi RA, et al. Premenstrual syndrome: prevalence, pattern and severity among female university students in Ekpoma, Nigeria. Trop J Obstet Gynaecol 2009; 26: 142-50.

38. Direkvand-Moghadam A, Sayehmiri K, Delpisheh A, Kaikhavandi S. Epidemiology of premenstrual syndrome: a systematic review and meta-analysis study. J Clin Diagn Res 2014; 8: 106-9.
39. Ikeako LC, Ezegwu HU, Nwafor MI, Nwaogu-Ikegojo EE. Pattern of premenstrual symptoms among pre-clinical medical students at the University of Nigeria. Orient J Med 2014; 26: 52-7.

40. Bakhshani NM, Mousavi MN, Khodabandeh G. Prevalence and severity of premenstrual symptoms among Iranian female university students. Pak Med Assoc 2009; 59: 205-8.

41. Uzochukwu UA, Patricia NA, Theophilus ON. The impact of pre-menarcheal training on menstrual practices and hygiene of Nigerian school girls. Pan Afr Med J 2009; 22: 9.

42. Adewuya AO, Loto OM, Adewumi TA. Pattern and correlates of premenstrual symptomatology amongst Nigerian University students. J Psycho Neur Endocrinol 2003; 28: 25-37.

43. Tenkir A, Fisseha N, Ayele B. Premenstrual syndrome, prevalence and its effect on academic and social performances if students in Jimma University, Ethiopia. Ethiop J Health Dev 2003; 17: 181-8.

44. Gollenberg AL, Hediger ML, Mumford SL, et al. Perceived stress and severity of premenstrual syndrome: the BioCycle study. J Womens Health 2010; 19: 959-67. 